\title{
Constant evolution of the Korean Journal of Medical Education
}

Young Hwan Lee

President, The Korean Society of Medical Education, Seoul, Korea

The Korean Journal of Medical Education (KJME) has finally been indexed in SCOPUS, and I would like to share this joy with all of our members. I am deeply grateful to the editor-in-chief, Young-Mee Lee, and to all of the editorial members for their hard work up until today. In addition, I would like to thank the former editor-in-chief, Sun Kim, and the deputy editor, Sun Huh, who were in charge of editing from 2005 to 2016. They contributed to developing the cornerstone for this splendid achievement.

Since the introduction of modern medicine in Korea in the late 19th century, medical education in Korea has developed remarkably throughout its history of more than 130 years. In particular, since the late 20th century, innovation and change has accelerated, and it was during this time that our journal made its first appearance. It has systematically accumulated the processes of this change ever since. Therefore, the KJME has served a very meaningful purpose in acting as an important historical datum regarding the development of medical education in Korea.
I look back on the history of the KJME from its first publication under the name "Hankuk Euhak Kyuyook" in June 1989, up to the present. In 2007, it was promoted to an A-class Korean Citation Index (KCI) journal in the field of natural sciences by the Korea Research Foundation, and it converted to an online journal from the June issue in 2014. In 2015, after changing its name to the current iteration, the KJME worked towards internationalization and was indexed in MEDLINE of the U.S. National Library of Medicine. In 2016, the KJME's full texts started to be published in English (from the March issue), and the journal was indexed in "PubMed Central." In 2017, it was selected as an excellent KCI journal in the evaluation of academic journals by the Korea Research Foundation. In 2019, it was promoted to a SCOPUS journal.

The KJME is now the only journal that is indexed in both PubMed and SCOPUS among medical education journals published in the Asian region. It has been reborn as a professional academic journal that is widely read and cited around the world by experts and
Received: November 22, 2019 • Revised: November 25, 2019 • Accepted: November 28, 2019 Corresponding Author: Young Hwan Lee (https://orcid.org/0000-0001-8377-5802) Department of Medical Humanities, Yeungnam University College of Medicine, 170 Hyeonchung-ro, Nam-gu, Daegu 42415, Korea

Tel: +82.53.640.6999 Fax: +82.53.629.2252 email: yhlee3535@ynu.ac.kr
Korean J Med Educ 2019 Dec; 31(4): 297-298. https://doi.org/10.3946/kjme.2019.139 eISSN: 2005-7288

(C) The Korean Society of Medical Education. All rights reserved. This is an open-access article distributed under the terms of the Creative Commons Attribution Non-Commercial License (http:// creativecommons.org/licenses/by-nc/3.0/), which permits unrestricted non-commercial use, distribution, and reproduction in any medium, provided the original work is properly cited. 
researchers in the fields of medicine and healthcare education.

Personally, I feel that the KJME has now taken on heavy responsibilities. Changes in the learning environment, teaching methods, educational contents, and evaluation will be continuously required in order to improve medical education. The demand for these changes is ultimately aimed at ensuring "educational authenticity." Educational authenticity can be obtained by minimizing any gaps that students might face in their future clinical practices between educational contexts in medical schools. It can be achieved by providing students with learning opportunities that are directly connected to real clinical situations, and with an authentic evaluation that is relevant to practical contexts. I would like the KJME to introduce, disseminate, and lead new insights and methods to achieve educational authenticity in medical education.

I believe that the constant evolution of the KJME stems from the support and contributions provided by medical educators and researchers. I sincerely ask you to become partners in a new journey, in which KJME will rise to become recognized as an internationally renowned academic journal.

\section{ORCID:}

Young Hwan Lee: https://orcid.org/0000-0001-8377-5802

Acknowledgements: None.

Funding: None.

Conflicts of interest: No potential conflict of interest relevant to this article was reported.

Author contributions: All work was done by YHL. 